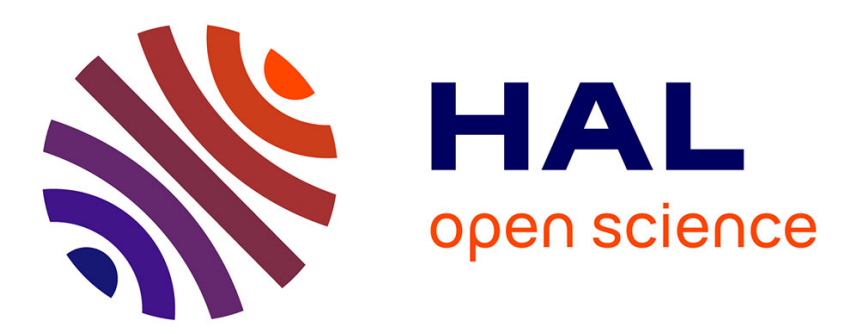

\title{
Influence of hydrogen bonds on glass transition and dielectric relaxations of cellulose
}

\author{
Frédéric Roig, Eric Dantras, Jany Dandurand, Colette Lacabanne
}

\section{To cite this version:}

Frédéric Roig, Eric Dantras, Jany Dandurand, Colette Lacabanne. Influence of hydrogen bonds on glass transition and dielectric relaxations of cellulose. Journal of Physics D: Applied Physics, 2011, 44 (4), pp.45403. 10.1088/0022-3727/44/4/045403 . hal-00589771

\section{HAL Id: hal-00589771 \\ https://hal.science/hal-00589771}

Submitted on 2 May 2011

HAL is a multi-disciplinary open access archive for the deposit and dissemination of scientific research documents, whether they are published or not. The documents may come from teaching and research institutions in France or abroad, or from public or private research centers.
L'archive ouverte pluridisciplinaire HAL, est destinée au dépôt et à la diffusion de documents scientifiques de niveau recherche, publiés ou non, émanant des établissements d'enseignement et de recherche français ou étrangers, des laboratoires publics ou privés. 


\title{
Influence of hydrogen bonds on glass transition and dielectric relaxations of cellulose
}

Frédéric Roig, Eric Dantras, Jany Dandurand and Colette Lacabanne

Physique des Polymères, Institut Carnot CIRIMAT UMR 5085, Université Paul Sabatier 118, route de Narbonne, 31062 Toulouse Cedex, France

E-mail: dantras@cict.fr

\begin{abstract}
The molecular dynamic in hydrated cellulose has been investigated by a combination of thermal analyses and dielectric spectroscopy. Differential Scanning Calorimetry (DSC) shows the dependence upon hydration of the glass transition temperature $\mathrm{T}_{\mathrm{g}}$. A physical ageing phenomenon has been observed. At the molecular scale, bound water is hydrogen bonded to polar sites of cellulose macromolecules. At the macroscopic scale, water molecules play the role of a plasticizer for cellulose lowering its $\mathrm{T}_{\mathrm{g}}$. Dynamic Dielectric Spectroscopy (DDS) combined with Thermostimulated Currents (TSC) have allowed us to follow more localized molecular mobility. The $\beta$ relaxation mode is characterized by activation entropies that vanish for higher water contents indicating molecular mobility localization. It is plasticized by water like the glass transition. This analogy is explained by a common origin of both mechanisms: the mobility of the cellulose backbone. The evolution of the $\gamma$ mode upon hydration follows an anti-compensation law. Water acts as an anti-plasticizer in a hydrogen bonded network.
\end{abstract}

PACS: 77.22.Gm, 77.84.Jd 


\section{Introduction}

Cellulose is probably the most studied biopolymer. Increasing $\mathrm{CO}_{2}$ stimulate photosynthesis of chlorophyll plants and potentially allow plants to increase production biomass in the order of 20\% [1]. The major structural component of the plant cell and the most important substance produced by plants is cellulose [2]. The large number of studies published on its properties is explained by important interests to optimize the natural resource consumption [3, 4], prevention of fire [5], bone regeneration [6], specific cellulose membranes $[7,8]$ or decrease the cost of cellulose extraction process by wood genetic modification [9] in paper industry for example.

Thermal stability has been characterized by thermogravimetry analysis (TGA) [10] and physical structure by differential scanning calorimetry (DSC) [11]. In the literature, thermogravimetry analyses of cellulose point out two weight losses; the first one in the range of 40 to $80{ }^{\circ} \mathrm{C}$ attributed to the water evaporation [11-13] and the second one in the temperature range of 200 to $400^{\circ} \mathrm{C}$, to polymer degradation. During this decomposition, the principal products are water and carbon dioxide $[5,11,12,14,15]$.

The glass transition of cellulose has been extensively studied [11, 16-18], generally by differential scanning calorimetry [19]. The determination of the glass transition temperature is not easy due to the presence of water [16] and to the weak fraction of amorphous phase [20]. Similar problem has been already noted for starch-based materials and various factors such as sample preparation, methods of adding water, effect of sample mass or heating rate influence have to be carefully considered [21]. According to Hatakeyama [20], physico-chemical properties of cellulose are mainly dependent upon amorphous regions. By x-ray diffractometry (XRD) the amorphous content of various kind of cellulose is measured. It reaches $30 \%$ for natural cellulose extracted from cotton linter [20]. Batzer and Kreibich [16] determine Tg by DSC but they have small changes in heat capacity. Szczesniak [11] has also small variation of heat capacity. Vittadini et al. [17] do not observe $T_{g}$ but molecular transition is found by nuclear magnetic resonance (NMR).

Dielectric dynamic spectroscopy (DDS) has been already used on polysaccharides like cellulose and its derivatives [22-29]. Four dielectric relaxations modes are usually observed $\gamma, \beta, \beta_{\text {wet }}$ and $\alpha$, in the order of increasing temperatures [22-29]. The dielectric properties of cellulose have been also investigated by combined DDS/TSC [28]. In the low temperature range $\left(\mathrm{T}<0{ }^{\circ} \mathrm{C}\right)$ where the molecular mobility is localized two modes are extracted; i.e. $\gamma$ and $\beta$ also observed in mechanical spectroscopy [30-31]. The $\gamma$ mode has been associated with side groups $\left(-\mathrm{CH}_{2} \mathrm{OH}\right.$ and 
-OH) mobility [22-28] and the $\beta$ mode with localized cooperative molecular mobility of the main chain $[28,29]$. The $\beta_{\text {wet }}$ relaxation mode is observable at room temperature and is not detected after intense drying. This mode is attributed by Einfeldt et al. [22-27] to the reorientation of polymer-water complexes formed at the polymer-water interface. At higher temperature $\left(\mathrm{T}>0^{\circ} \mathrm{C}\right)$ the molecular mobility is delocalized. $\alpha$ relaxation mode is assigned to cooperative delocalized mobility of nanometric sequences of the main chain [28]. It is the dielectric manifestation of glass transition.

According to Einfeldt et al., the properties of polysaccharides as cellulose can be changed drastically by adding small amounts of water. Moreover the ability of cellulose to interact with water is not reversible, after consecutive dryings the water retention value of cellulose decreases drastically. This phenomenon is known as hornification $[22,23,26]$. The influence of hydration on relaxation modes of polysaccharides is noticeable. Einfeldt compares dry and wet celluloses. The activation energy $E_{a}$ of the local main chain dynamics increases contrary to the pre-exponential factor $\tau_{0}$ which is reduced. The $\gamma$ process is more cooperative in wet celluloses than in dry celluloses [25]. Measurements on others polysaccharides as starch and dextran confirm this results [22]. A $\beta_{\text {wet }}$ relaxation mode can be observed in all wet polysaccharides in the room temperature range $\left(0-60^{\circ} \mathrm{C}\right)$ [22-27]. This mode is not observed anymore after drying the sample [22-27]. The hydration influence of polysaccharides on their dielectric properties can be interpreted by several hypotheses: one the one hand, the OH-groups of glucosidic units form hydrogen bonds with water molecules. These bound water molecules increase the dipolar moment and the moment of inertia of movable groups. Moreover the stiffness of the polymer chain increases because water molecules bonded produce a bridge along the chain and between two adjacent chains. On the other hand, the macroscopic flexibility of cellulosic fibrous sample becomes more important thanks to the swelling power of water [2, 22, 25].

In spite of the abundant literature, some points as the complex interaction of water with cellulose macromolecule remains particularly obscure and multiple interpretations exist [32, 33, 34]. We have already shown that the fruitful synergy of DDS/TSC combination allows us to investigate the changes within the molecular dynamics of cellulose caused by water influences [28, 29]. These results stimulate us to study the issue of cellulose glass transition with different water contents using the classical techniques of DSC. A complete dielectric study will be performed and particular attention will be paid to specific interactions between polymer and water. 


\section{Experimental}

\subsection{Materials}

The cellulose provided by Sigma-Aldrich is a white microcrystalline powder $(20 \mu \mathrm{m})$ extracted from cotton linters, with a number-average molecular weight between 36000 and 40000 . The degree of polymerization is between 222 and 246. The initial water content has been determined by thermogravimetry experiments near $5 \%$. Cotton fibres extracted from a natural plant have been also investigated (purity 95\%).

Samples with different hydration levels were prepared. The $0 \%$ hydration was obtained according to the following procedure: sample was placed on $\mathrm{P}_{2} \mathrm{O}_{5}$ during $72 \mathrm{~h}$. Constant humidity level was reached by storage at $25^{\circ} \mathrm{C}$ over saturated salt solutions during $72 \mathrm{~h}$. Saturated salt solutions of $\mathrm{MgCl}_{2}, 6 \mathrm{H}_{2} \mathrm{O}$ and $\mathrm{NaCl}$ allow us to obtain $3 \%$ and $7 \%$ of hydration respectively. In the case of $\mathrm{NaCl}$ solution, for a double storage time, $13 \%$ was reached.

The water content was determined from the weight loss after drying. The hydration level $\mathrm{h}(\%)$, was defined as follows:

$$
h(\%)=\frac{m_{\text {water }}}{m_{\text {cellulose }}} \times 100
$$

Where $m_{\text {water }}$ is the water mass and $m_{\text {cellulose }}$ is the mass of cellulose sample after drying.

\subsection{Methods}

\subsubsection{Thermogravimetry}

Thermogravimetry analyses were performed with a TGA Q50 Thermal Analyser in open pans under nitrogen flow from room temperature to $600{ }^{\circ} \mathrm{C}$ at $10^{\circ} \mathrm{C} / \mathrm{min}$. Sampling of cellulose was twofold: powder or pellets. Activation energy of cellulose degradation is analysed using Broido method [35]:

$$
\begin{gathered}
\ln (-\ln (1-\alpha))=\ln (K)-\frac{\Delta E}{R T} \\
\alpha=\frac{m_{0}-m}{m_{0}-m_{\infty}}
\end{gathered}
$$

Where $m_{0}$ is the initial mass and $m_{\infty}$ is the final mass of the sample. 


\subsubsection{Standard differential scanning calorimetry}

The DSC thermograms were recorded with a DSC 2920 TA Instrument. The samples in pellets gave better results than powder (associated with signal-to-noise ratio). Cellulose powder was pressed under controlled pressure of about $75 \mathrm{MPa}$ to form pellets. Samples were sealed into aluminium pans, and empty pans were used as reference. Empty pans were also sealed. Experiments were performed in the -20 to $180^{\circ} \mathrm{C}$ temperature range with a heating rate $20^{\circ} \mathrm{C} / \mathrm{min}$ (and a cooling rate $\mathrm{q}_{\mathrm{c}}=20^{\circ} \mathrm{C} / \mathrm{min}$ ). This heating rate has been chosen to perform the thermal signal [36].

\subsubsection{Dynamic dielectric spectroscopy (DDS)}

A BDS 4000 Novocontrol broadband dielectric spectrometer system was used to obtain the dielectric relaxation map in a wide temperature and frequency range. The sample was inserted between two plan parallel electrodes. It was stimulated by a sinusoidal electrical field at a given temperature and the complex impedance is recorded during frequency scan. The measurements were carried out in the frequency range of $10^{-1}-10^{6} \mathrm{~Hz}$ from $-150^{\circ} \mathrm{C}$ to $200^{\circ} \mathrm{C}$ by steps of $5^{\circ} \mathrm{C}$. The complex dielectric permittivity $\varepsilon^{*}(\omega)$ was deduced thanks to complex impedance by the relation:

$$
\varepsilon^{*}(\omega)=\frac{1}{i \omega \cdot C_{0} Z *(\omega)}=\varepsilon^{\prime}-i \varepsilon^{\prime \prime}
$$

With $\mathrm{C}_{0}$ is the capacitance in vacuum, $\omega$ the pulsation $(\omega=2 \pi \mathrm{f}), \mathrm{Z}^{*}$ the complex impedance. Relaxation modes are described by the Havriliak-Negami function [37]:

$$
\varepsilon^{*}(\omega)=\varepsilon_{\infty}+\frac{\Delta \varepsilon}{\left[1+\left(i \omega \tau_{H N}\right)^{\alpha_{H N}}\right]^{\beta_{H N}}}
$$

With $\tau_{\mathrm{HN}}$ is the relaxation time of the Havriliak-Negami $(\mathrm{HN})$ equation, $\alpha_{\mathrm{HN}}$ is the width and $\beta_{\mathrm{HN}}$ the asymmetry of the mode.

In cellulose, the temperature dependence of relaxation times follows an Arrhenius- Eyring equation:

$$
\tau(T)=\frac{h}{k_{B} \cdot T} \cdot \exp \left[-\frac{\Delta S}{R}\right] \cdot \exp \left[\frac{\Delta H}{R T}\right]
$$

Where $\mathrm{k}_{\mathrm{B}}$ is the Boltzmann's constant, $\mathrm{R}$ is the gas constant; $\mathrm{h}$ is the Planck's constant, $\Delta \mathrm{H}$ the activation enthalpy and $\Delta \mathrm{S}$ the activation entropy. 


\subsubsection{Thermo stimulated currents (TSC)}

TSC measurements were carried out with a home-made equipment previously described [19]. Pellets $(\phi=0.8 \mathrm{~cm})$ were inserted between two plate steel electrodes. Sample cell was filled with dry helium. For recording complex thermograms, the sample was polarized by an electrostatic field $\mathrm{E}_{\mathrm{p}}=$ $1.2 \mathrm{kV} / \mathrm{mm}$ during $\mathrm{t}_{\mathrm{p}}=2 \mathrm{~min}$ over a temperature range from the polarization temperature $\mathrm{T}_{\mathrm{p}}$ down to the freezing temperature $\mathrm{T}_{0}$. Then the field was turned off and the depolarization current was recorded with a constant heating rate $\left(\mathrm{q}_{\mathrm{h}}=+7^{\circ} \mathrm{C} \cdot \mathrm{min}^{-1}\right)$, the equivalent frequency of the TSC spectrum was $\mathrm{f}_{\mathrm{eq}} \sim$ $10^{-2}-10^{-3} \mathrm{~Hz}$. Elementary TSC thermograms were obtained with a poling window of $5^{\circ} \mathrm{C}$. Then the field was removed and the sample cooled down to a temperature $\mathrm{T}_{\mathrm{cc}}=\mathrm{T}_{\mathrm{p}}-40^{\circ} \mathrm{C}$. The depolarization current was normalized to be homogeneous with dipolar conductivity $\sigma$ and it was recorded with a constant heating rate $\mathrm{q}_{\mathrm{h}}$.The series of elementary thermograms was recorded by shifting the poling window by $5^{\circ} \mathrm{C}$ towards higher temperature.

\section{Results and discussion}

\subsection{Thermal stability}

TGA experiments have been carried out in order to define the stability and the influence of sampling (powder or pellet). Figure 1 shows two thermograms of powder and pellet respectively. For powder two weight losses are observed, i.e. $60^{\circ} \mathrm{C}$ and $343^{\circ} \mathrm{C}$. First one is associated with water according to infra-red spectrometer and second one with the cellulose degradation. These two events are consistent with literature $[4,5,11-13,38-40]$. For pellets, a slight shift of these two weight losses toward higher temperatures is observed, i.e. $82^{\circ} \mathrm{C}$ and $355^{\circ} \mathrm{C}$. This shift is probably due to the increase of hydrogen bonds interactions associated with the decrease of length between hydrophilic groups.

Broido method [35] has been used to determine activation energy of degradation. Results are shown in Figure 2 and reported in Table 1. Three sampling of cellulose (i.e. powder, pellet and fibres) and three pressures are analysed. The activation energy of pellets, near $238 \mathrm{~kJ}^{-\mathrm{mol}^{-1}}$, is higher than powder and fibres. This value is consistent with Varhegyi et al data [41]. In the case of pellets, we do not observe influence of pressure on this physical parameter. Analogous behaviour has been found in tablets of microcrystalline cellulose [42]. Consequently, pellets can be used for dielectric analysis. The stability temperature range as defined by TGA reaches $200^{\circ} \mathrm{C}$. 


\subsection{Thermal transitions}

DSC thermograms of cellulose are reported in Figure 3. Four consecutive heating cycles have been carried out to obtain a repeatable result in dehydrated cellulose. A large endothermic peak associated with water loss during the heating [11, 43] is observed for the first thermogram. For the following thermograms the heat capacity step characteristic of the glass transition is pointed out. The $\mathrm{T}_{\mathrm{g}}$ of dehydrated cellulose is found at $84 \pm 1^{\circ} \mathrm{C}$ with a $\Delta \mathrm{C}_{\mathrm{p}}=0.30 \pm 0.01 \mathrm{~J} /\left(\mathrm{g} .{ }^{\circ} \mathrm{C}\right)$. The $\Delta \mathrm{C}_{\mathrm{p}}$ value is comparable with values measured for synthetics polymers [44].

Figure 4 reports an endothermic peak superimposed to $\mathrm{T}_{\mathrm{g}}$ appearing when the sample was heated at $60^{\circ} \mathrm{C}$ for different duration from $15 \mathrm{~min}$ to $3 \mathrm{~h}$. This weak phenomenon is reversible so that it looks like physical ageing $[45,46]$. Its kinetics must be fast since it is independent from annealing time contrarily with usual physical ageing. It is interesting to report here that physical ageing has been observed by thermo stimulated currents in amorphous ethyl cellulose [47]. At this stage, the phenomenon observed in cellulose may be attributed to the disruption of hydrogen bonds in the amorphous phase.

Figure 5 shows heat flow measurements of cellulose with water content from $0 \%$ to $5 \%$. The glass transition is strongly dependent upon hydration. $\mathrm{T}_{\mathrm{g}}$ and $\Delta \mathrm{C}_{\mathrm{p}}$ of cellulose decreases when the hydration level increases. A strong plasticization effect is observed and confirms previous results $[11,16,18]$.

The properties of biopolymers are dependent on their hydration due to hydrophilic groups [18]. Authors differentiate three kind of water in biopolymers: free water, freezing-bound water and non-freezing bound water [11, 42, 48, 49].

This classical thermal analysis reveals that water interacts with the polymer; i.e. free water is dismissed. The following dielectric analysis allows us to shed some light on this behaviour.

\subsection{Isothermal dynamic dielectric response}

The complex dielectric permittivity is explored by DDS. In order to investigate the water influence on the dielectric response, experiments are carried out with different hydration levels. Figure 6 shows the relaxation map of 7\% hydration cellulose. These three-dimensional diagrams point out four dielectric events: at low temperature two broad secondary relaxation modes called $\gamma$ and $\beta$, at higher temperature a wide quasi-isothermal relaxation and conductivity phenomenon labelled $\beta$ ' and $\sigma$ respectively. The $\alpha$ relaxation mode associated with the dielectric manifestation of glass transition is hidden by this conduction phenomenon. The $\sigma$ electrical conduction manifestation has been already associated with charge transport [26] or Maxwell-Wagner-Sillars effect [28]. 
The $\tan (\delta)$ loss factor of cellulose with different water content; i.e. $0 \%$ to $7 \%$ is shown in Figure 7. In the low temperature region, $\gamma$ relaxation mode is pointed out for each hydration level contrary to $\beta$ relaxation mode which is only visible for 3 and $7 \%$. In consequence for $5 \%$ water contents and near $-50^{\circ} \mathrm{C}$, the tan $(\delta)$ loss factor curve is below $3 \%$. At higher temperatures $\left(>80^{\circ} \mathrm{C}\right) \mathrm{a}$ similar behaviour is observed due to the influence of $\alpha$ relaxation mode hidden by conduction phenomenon. From $-50^{\circ} \mathrm{C}$ to $80^{\circ} \mathrm{C}$ the additional dielectric contribution labelled $\beta$, appears for hydrated samples. This peak is also observed on the three-dimensional map of $\varepsilon$ " (Figure 6). The strength of this mode increases with the hydration level. Such a $\beta$ ' relaxation mode, has been already reported in the literature $[42,50,51]$ and it has been associated with conformational changes of confined water. Banys et al. [50] confirms this molecular origin in porous materials.

The relaxation times $\tau$ have been extracted from dielectric data and reported in the Arrhenius diagram of Figure 8 . The relaxation times of the two secondary relaxation modes are well fitted by an Arrhenius law but their behaviour is dependent upon hydration level. For the $\gamma$ mode, the series of relaxation times corresponding to various hydration levels converges at low temperature and follows an "anti-compensation" law:

$$
\tau(T)=\tau_{C} \cdot \exp \left[\frac{\Delta H}{R}\left(\frac{1}{T}-\frac{1}{T_{C}}\right)\right]
$$

Where $\mathrm{T}_{\mathrm{c}}=-130^{\circ} \mathrm{C}$ and $\tau_{\mathrm{c}}=2.4 \mathrm{~s}$ are the temperature and the time of the convergence point respectively. This $\tau_{\mathrm{c}}$ value is quite high for a low temperatures relaxation. As comparison, it is near $\tau_{\mathrm{c}}$ value of the lignin main relaxation [52]

It is interesting to note the value of $\Delta \mathrm{H}=40 \mathrm{~kJ} / \mathrm{mol}$ is comparable with the one of hydrogen bond. The activation parameters are reported in Figures 9 and 10. These results are coherent with published data from mechanical and dielectric studies [28-31, 49]. The activation energy of the $\gamma$ mode increases with the hydration level whereas it decreases for the $\beta$ mode. The increase of the activation energy indicates the decrease of its molecular mobility [23, 28, 53]. The hydroxyl and hydroxymethyl groups form water-polymer complexes. Hydrogen bonds decrease the water-polymer complex mobility. Hydration plays the role of an anti-plasticizer for the $\gamma$ mode. The decrease of the activation energy with hydration for the $\beta$ mode indicates that its molecular mobility increases. The water molecules interfere with existing hydrogen bonds, increasing the free volume between the polymer chains and reducing the hindrance for the local chain mobility. Hydration plays the role of a plasticizer for the $\beta$ mode. It can involve in the same behaviour for the $\beta$ mode of epoxy assemblies associated 
with hydroxyether entities. Chevalier et al. [54] observe also the low temperature convergence point and the decrease of the activation energy with the increasing of hydration level due to hydrothermal ageing. The evolution of mobility is linked with the physical environment modification. These dynamic dielectric data have been completed towards lower frequencies by thermostimulated current experiments.

\subsection{Correlation with non isothermal dielectric response}

The normalized depolarization current $\sigma$ is plotted versus temperature in Figure 11, for different water content. In the low temperature range and for $0 \%$ hydration two relaxation modes are observed. The $\gamma$ relaxation mode assigned to the side groups' reorientation is located at $-135^{\circ} \mathrm{C}$. The $\beta$ relaxation mode attributed to localized movements of short sequences of the main chain of cellulose is pointed out at $-65^{\circ} \mathrm{C}$. Contrary to the $\beta$ relaxation mode, the maximum of the $\gamma$ relaxation mode increases with the hydration level from $-135{ }^{\circ} \mathrm{C}$ at $0 \%$ to $-120{ }^{\circ} \mathrm{C}$ at $7 \%$. We observe a merging of these two relaxation modes upon increasing hydration level. These results are coherent with SDD; i.e. hydration plays the role of an anti-plasticizer for the $\gamma$ mode and a plasticizer for the $\beta$ mode. The antiplasticization phenomenon due to hydration is also observed in micromechanical spectroscopy as shown by Lamure et al. from studies of the main retardation mode associated with glass transition of proteoglycan subunits [55]. Fractional polarizations allow us to extract activation parameters for different hydration state. A series of elementary thermograms is obtained and reported in Figure 12 for $0 \%$ hydration.

Results of the two dielectric methods are reported for each hydration state. The $\beta$ DDS relaxation mode is detectable for 3\% and 7\% hydration level only. According to Montès et al. [30, 31, 56], the $\beta$ relaxation mode has been associated with cellulose moisture content; it is not always detectable by DDS. In Fig. 13, Arrhenius diagram of DDS and TSC data is shown for 3\% of water. The relaxation times obtained by DDS are extrapolated until TSC data; a good correlation is performed. The correlation between $\gamma$ and $\beta$ modes in DDS and TSC allows us to confirm the molecular origin of these two modes. Then, the $\beta$ mode can be follow for each state of hydration by TSC.

The activation enthalpy versus temperature for $\gamma$ and $\beta$ relaxation modes are reported in Figure 14 with the Starkweather line [57] associated with the null activation entropy. The experimental points related to the $\gamma$ mode, lie close to the Starkweather line indicating that the localized mobility of the side groups is not cooperative. Contrarily, activation enthalpies of the $\beta$ mode 
depart from the null activation entropy line reflecting a cooperative mobility of the $\beta_{1-4}$ glycosidic bonds of cellulose.

The influence of hydration level on the activation enthalpies versus temperature for the elementary process of $\gamma$ and $\beta$ relaxation modes are reported in Figure 15. The enthalpy range and $\Delta \mathrm{H}_{\max }$ values decrease when the hydration level increases. The cooperative behaviour of the $\beta$ relaxation is strongly dependent upon hydration. For water contents between $0 \%$ and $2.5 \%$, the $\beta$ relaxation is characterized by a cooperative behaviour; otherwise for hydration level between $2.5 \%$ and $7 \%$, a non cooperative behaviour is exhibited. This evolution has been assigned to an increase of the hydrogen bond density leading to a more localized cooperative mobility.

\section{Conclusion}

The combination of both thermal analyses and dielectric spectroscopy has been applied to a thorough investigation of the molecular dynamic in hydrated cellulose.

The thermal stability of the polymer and the initial water content is assessed using TGA. Thermal behaviour of cellulose is dependent of morphology of samples. The activation energy of degradation for pellets is higher than for the others forms (fibres, powder). Contrarily, pressure does not affect the degradation behaviour of pellets.

Original data have been extracted from DSC showing the influence of water on the viscoelastic behaviour of cellulose through the analysis of the dependence upon hydration of the glass transition temperature $\mathrm{T}_{\mathrm{g}}$. At the molecular scale, bound water is hydrogen bonded to polar sites of cellulose macromolecules. At the macroscopic scale, water molecules play the role of a plasticizer for cellulose lowering its $\mathrm{T}_{\mathrm{g}}$.

DDS combined with TSC has allowed us to follow more localized molecular mobility occurring in the glassy state as a function of hydration. According to the literature, the origin of the $\beta$ relaxation mode is localized movements of the $\beta_{1-4}$ glycosidic bonds of cellulose. This mode is characterized by activation entropies that vanish for higher water contents indicating a localization of the molecular mobility. It is plasticized by water like the glass transition. This analogy is explained by a common origin of both mechanisms: the mobility of the cellulose backbone. In fact, they differentiate only by the scale of the mobile units.

From previous works, the $\gamma$ relaxation mode has been attributed to the molecular mobility of the side groups of glycosidic rings. The behaviour of this $\gamma$ mode upon hydration is opposite to the previous ones. The series of relaxation times corresponding to various hydration levels follow an anticompensation law with an activation enthalpy comparable with the one of hydrogen bond. Water acts as an anti-plasticizer in a hydrogen bonded network involving $-\mathrm{CH}_{2} \mathrm{OH}$ and $-\mathrm{OH}$ groups with water 
molecules. It is interesting to note here that such an arrangement is common to biopolymers containing glycosidic rings. 


\section{References}

[1] Seguin B 2003 C.R. Geoscience 335 569-75

[2] Wagner G and Fengel D 1984 Wood: Chemistry Ultrastructure Reactions ed W De Gruyter

[3] Gani A and Naruse I 2007 Renewable Energy 32 649-61

[4] Hanakoa T, Inoue S, Uno S, Ogi T and Minowa T 2005 Biomass et Bioenergy 28 69-76

[5] Kaloustian J, El-Moselhy T F and Portugal H 2003 Thermochimica Acta 401 77-86

[6] Barbosa M A, Granja P L, Barrias C C and Amaral I F 2005 ITBM-RBM 26 212-17

[7] Wang Z H, Chien W C, Yue T W and Tang S H 2008 Journal of Membrane Science 310 1418

[8] Galop M, Lamure A and Lacabanne C 2000 Journal of Applied Polymer Science 78(1) 8-13

[9] Boudet A, Kajita S, Grima-Pettinati J and Goffner D 2003 TRENDS in Plant Science 8(12) $576-81$

[10] Shlensky O F and Vaynshteyn E F 1989 Journal of Thermal Analysis 35 1477-82

[11] Szczesniak L and Rachocki A 2007 Cellulose 15(3) 445-51

[12] Devallencourt C, Saiter J M and Capitaine D 1996 Polymer Degradation and Stability 52 32734

[13] Devallencourt C, Saiter J M and Capitaine D 1999 Polymer Engineering and Science 39(3) 413-21

[14] Agrawal R K 1988 The Canadian Journal of Chemical Engineering 66 403-12

[15] Shafizadeh F 1968 Advances in Carbohydrate Chemistry 23 419-74

[16] Batzer H and Kreibich U T 1981 Polymer Bulletin 5 585-90

[17] Vittadini E, Dickinson L C and Chinachoti P 2001 Carbohydrate Polymers 46 49-57

[18] Salmèn N L and Back E L 1977 Tappi 60(12) 137-40

[19] Teyssèdre G and Lacabanne C 1996 Techniques De L'Ingénieur Traité Analyse Et Caractérisation P3770 pp 1-7

[20] Hatakeyama T. 1989 Structure and properties of the amorphous region of cellulose Cellulose Structural And Functional Aspects J F Kennedy et al ed (Chichester: Halsted Press John Wiley \& Sons) pp 46-52

[21] Yu L and Christie G 2001 Carbohydrate Polymers 46 179-84

[22] Einfeldt J, Meißner D and Kwasniewski A 2000 Macromolecular Chemistry and Physics 201(15) 1969-75

[23] Einfeldt J, Meißner D, Kwasniewski A, Gruber E and Henricks R 2000 Macromolecular Materials and Engineering 283 7-14

[24] Meißner D, Einfeldt J and Kwasniewski A 2000 Journal of Non-Crystalline Solids 275 199209 
[25] Einfeldt J, Meißner D and Kwasniewski A 2001 Progress in Polymer Science 26 1419-72

[26] Einfeldt J, Meißner D and Kwasniewski A 2003 Journal of Non-Crystalline Solids 320 40-55

[27] Einfeldt J, Meißner D and Kwasniewski A 2004 Cellulose 11 137-50

[28] Jafarpour G, Dantras E, Boudet A and Lacabanne C 2007 Journal of Non-Crystalline Solids $3534108-15$

[29] Jafarpour G, Roig F, Dantras E, Boudet A and Lacabanne C 2009 Journal of Non-Crystalline Solids 355 1669-72

[30] Montès H, Mazeau K and Cavaillé J Y 1997 Macromolecules 30 6977-84

[31] Montès H, Mazeau K and Cavaillé J Y 1998 Journal of Non-crystalline Solids 235-237 41621

[32] Kent M and Meyer W 1983 Journal of Physics D: Applied Physics 16 915-25

[33] Sugimoto H, Miki T, Kanayama K and Norimoto M 2008 Journal of Non-Crystalline Solids $3543220-24$

[34] Švedas V 1998 Journal of Physics D: Applied Physics 31 1752-6

[35] Broido A 1969 Journal of Polymer Science A-2 7 1761-73

[36] Peng L, Long Y, Hongsheng L, Ling C and Lin L 2009 Carbohydrate Polymers 77 250-3

[37] Havriliak S and Negami S 1966 Journal of Polymer Science C 14 99-117

[38] Kifani-Sahban F, Belkbir L and Zoulalian A 1996 Thermochimica Acta 284 341-9

[39] Franceschi E, Luciano G, Carosi F, Cornara L and Montanari C 2004 Thermochimica Acta 418 39-45

[40] Sun J X, Sun X F, Zhao H and Sun R C 2004 Polymer Degradation and Stability 84 331-339.

[41] Várhegyi G and Jakab E 1994 Energy \& Fuels 8 1345-52

[42] Nilsson M, Alderborn G, and StrØmme M 2003 Chemical Physics 295 159-165

[43] Ford J L 1999 International Journal of Pharmaceutics 179 209-28

[44] Wunderlich B 2005 Thermal Analysis Of Polymeric Materials (Berlin: Springer New York: Heidelberg)

[45] Struik L C E 1978 Physical Aging in Amorphous Polymers and Other Materials (Amsterdam: Elsevier)

[46] Samouillan V, André C, Dandurand J and Lacabanne C 2004 Biomacromolecules 5 958-64

[47] Diogo H P and Moura-Ramos J J 2009 Journal of Polymer Science: B Polymers Physics 47 $820-9$

[48] Nakamura K, Hatakeyama T and Hatakeyama H 1981 Textile Research Journal 51 607-13

[49] Hatakeyama H and Hatakeyama T 1998 Thermochimica Acta 308 3-22

[50] Banys J, Kinka M, Macutkevič J, Voelkel G, Boehlmann W, Umamaheswari V, Hartmann M, and Poeppl A 2005 Journal of Physics: Condensed Matter 17 2843-57

[51] Einfeldt J and Kwasniewski A 2002 Cellulose 9 225-38 
[52] Jafarpour G, Dantras E, Boudet A, and Lacabanne C 2008 Journal of Non-Crystalline Solids $3543207-14$

[53] Henry F, Costa L C and Devassine M 2005 European Polymer Journal 41 2122-26

[54] Chevalier M, Dantras E, Tonon C, Guigue P, Lacabanne C, Puig C and Durin C 2010 Journal of Applied Polymer Science 115 1208-14

[55] Lamure A, Harmand M F and Lacabanne C 1990 Journal of biomedical materials research 24 $735-47$

[56] Montès H and Cavaillé J Y 1999 Polymer 40 2649-57

[57] Starkweather H W 1981 Macromolecules 14 1277-81 


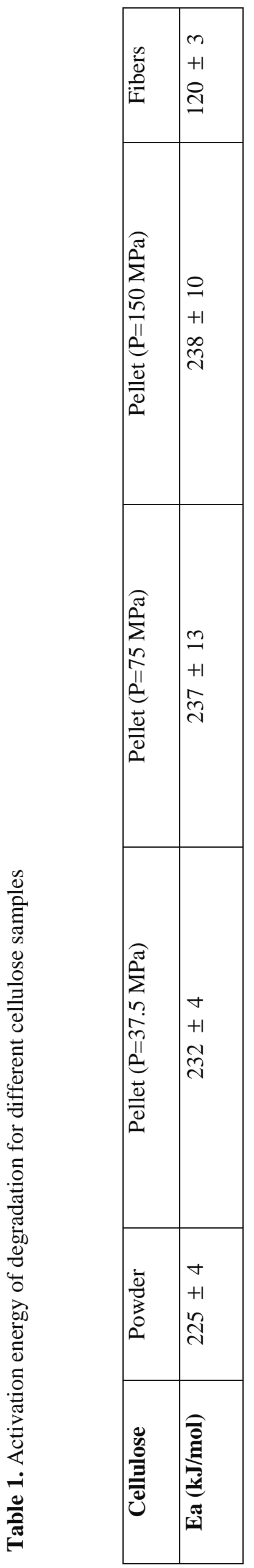




\section{Figure captions:}

Figure 1: Thermogravimetry thermograms for cellulose powder and pellet, from room temperature to $550^{\circ} \mathrm{C}$ at $10^{\circ} \mathrm{C} / \mathrm{min}$.

Figure 2: Broido's representation for different samples of cellulose.

Figure 3: Heat flow thermograms of cellulose pellets for four successive scans from $0^{\circ} \mathrm{C}$ to $180^{\circ} \mathrm{C}$ at $20^{\circ} \mathrm{C} / \mathrm{min}$.

Figure 4: DSC thermograms of cellulose after different annealing times from $20^{\circ} \mathrm{C}$ to $180^{\circ} \mathrm{C}$ at $20^{\circ} \mathrm{C} / \mathrm{min}$.

Figure 5: DSC thermograms of hydrated cellulose from $30^{\circ} \mathrm{C}$ to $120^{\circ} \mathrm{C}$, recorded at $20^{\circ} \mathrm{C} / \mathrm{min}$. The hydration level $\mathrm{h}$ is indicated for each thermogram.

Figure 6: Imaginary part of dielectric permittivity versus temperature $\left(-160{ }^{\circ} \mathrm{C}\right.$ to $\left.200^{\circ} \mathrm{C}\right)$ and frequency $\left(10^{-1} \mathrm{~Hz}\right.$ to $\left.10^{6} \mathrm{~Hz}\right)$, for cellulose pellets with $7 \%$ water content.

Figure 7: Tan $(\delta)$ dielectric loss factor versus temperature $\left(-160\right.$ to $\left.200^{\circ} \mathrm{C}\right)$ at $1 \mathrm{~Hz}$ for cellulose at different hydration levels

Figure 8: Arrhenius diagram of the low temperature relaxation modes $(\gamma$ and $\beta$ ) obtained by DDS for cellulose at different water contents.

Figure 9: Activation energy of $\gamma$ and $\beta$ mechanical and dielectric relaxation modes for different moisture contents for cellulose.

Figure 10: Activation entropy of $\gamma$ and $\beta$ mechanical and dielectric relaxation modes for different moisture contents for cellulose.

Figure 11: Complex TSC themogram of cellulose at four states of hydration from $-160^{\circ} \mathrm{C}$ to $-10^{\circ} \mathrm{C}$ at $7^{\circ} \mathrm{C} / \mathrm{min}$.

Figure 12: Complex TSC themogram with their associated elementary thermograms for $\gamma$ and $\beta$ relaxation modes $\left(-160^{\circ} \mathrm{C}\right.$ to $0^{\circ} \mathrm{C}$ at $\left.7^{\circ} \mathrm{C} / \mathrm{min}\right)$ for cellulose in the dehydrated state 
Figure 13: Arrhenius diagram from combined DDS and TSC in the low temperature range $\left(\mathrm{T}<0^{\circ} \mathrm{C}\right)$ for $3 \%$ hydrated cellulose

Figure 14: Activation enthalpy versus temperature for the elementary thermograms constituting the low temperature relaxation modes in dehydrated cellulose.

Figure 15: Activation enthalpy versus temperature for the elementary thermograms constituting the low temperature relaxation modes for cellulose at four states of hydration. 


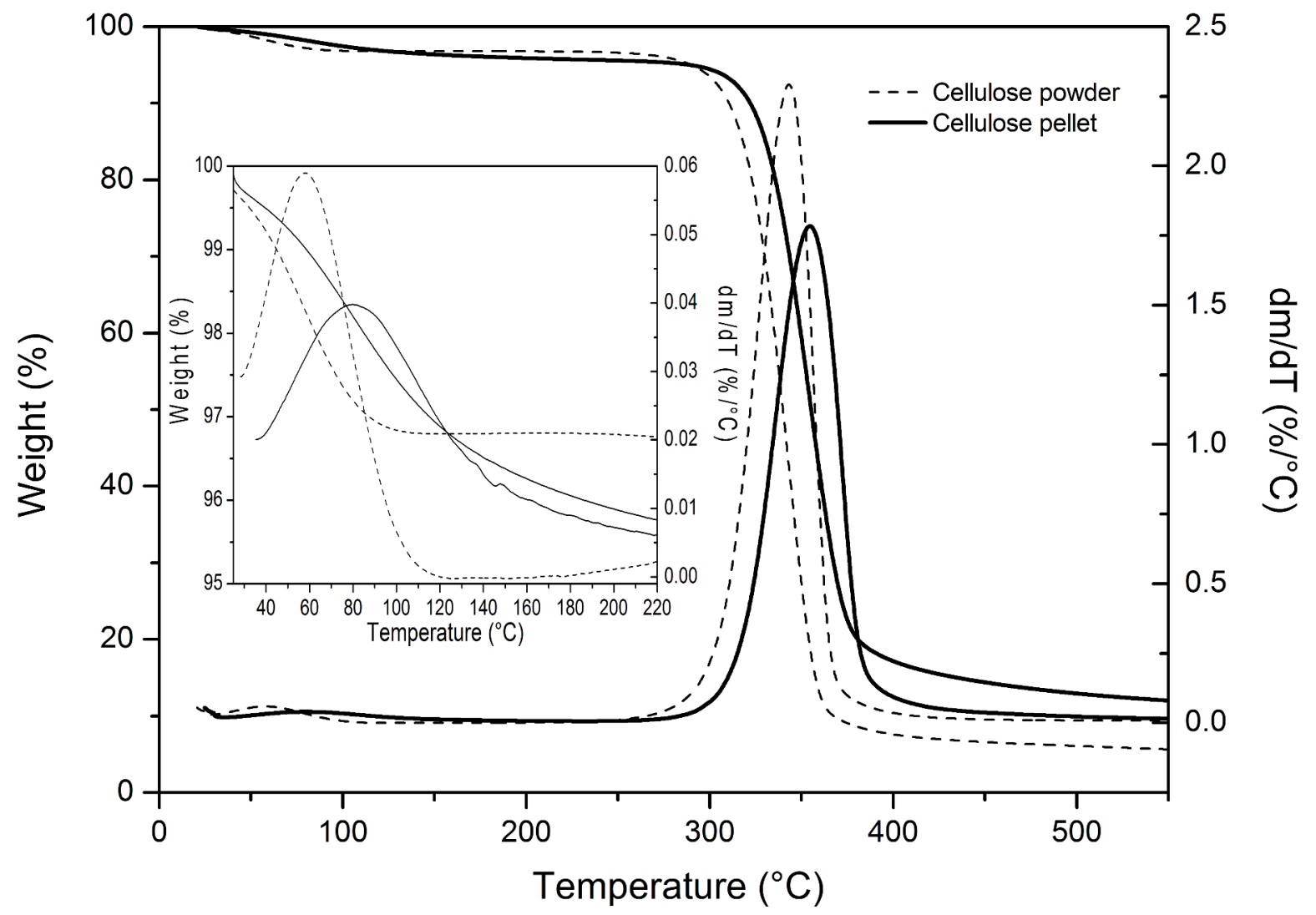

Figure 1 (Figure1.tif) 


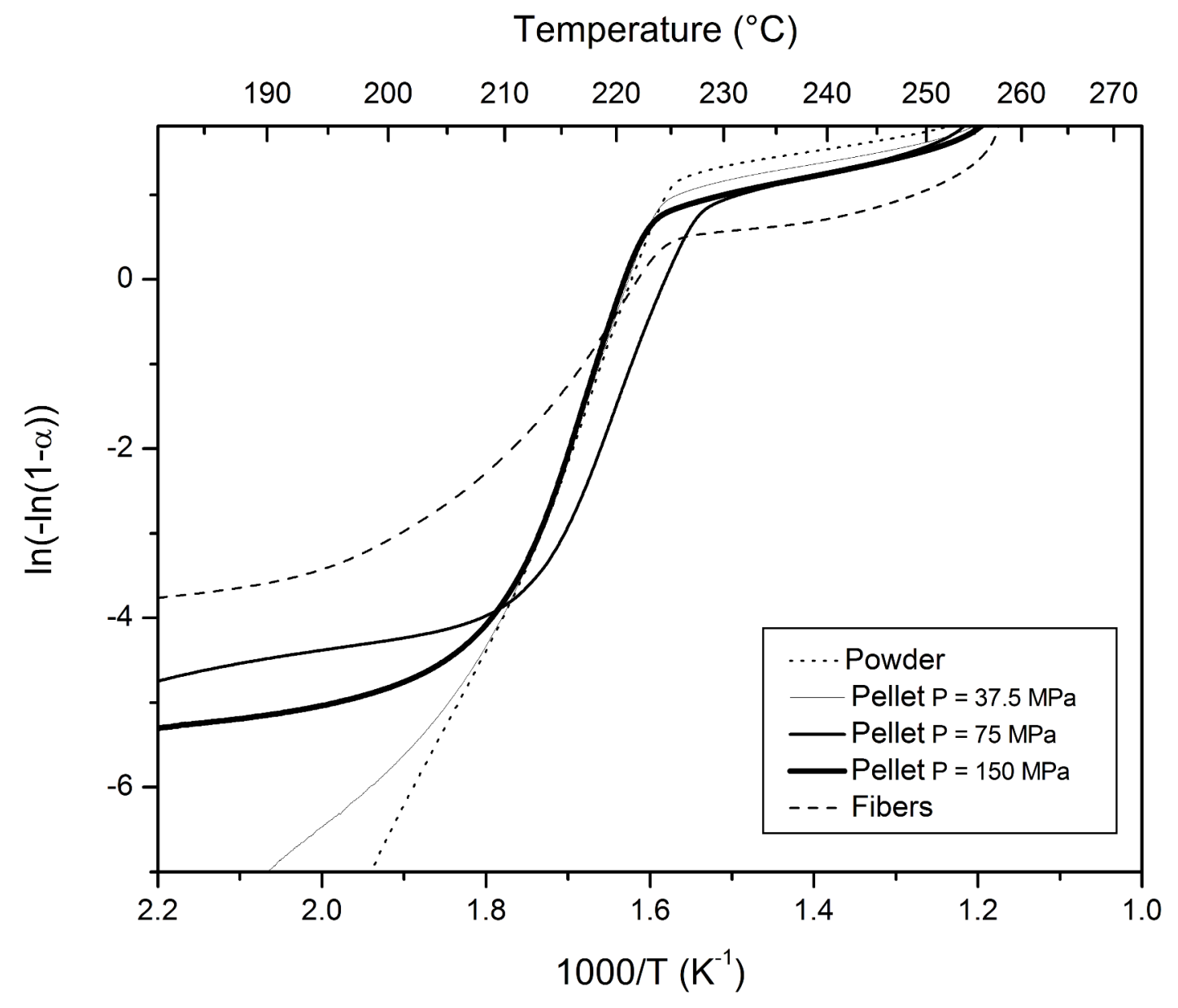

Figure 2 (Figure2.tif) 


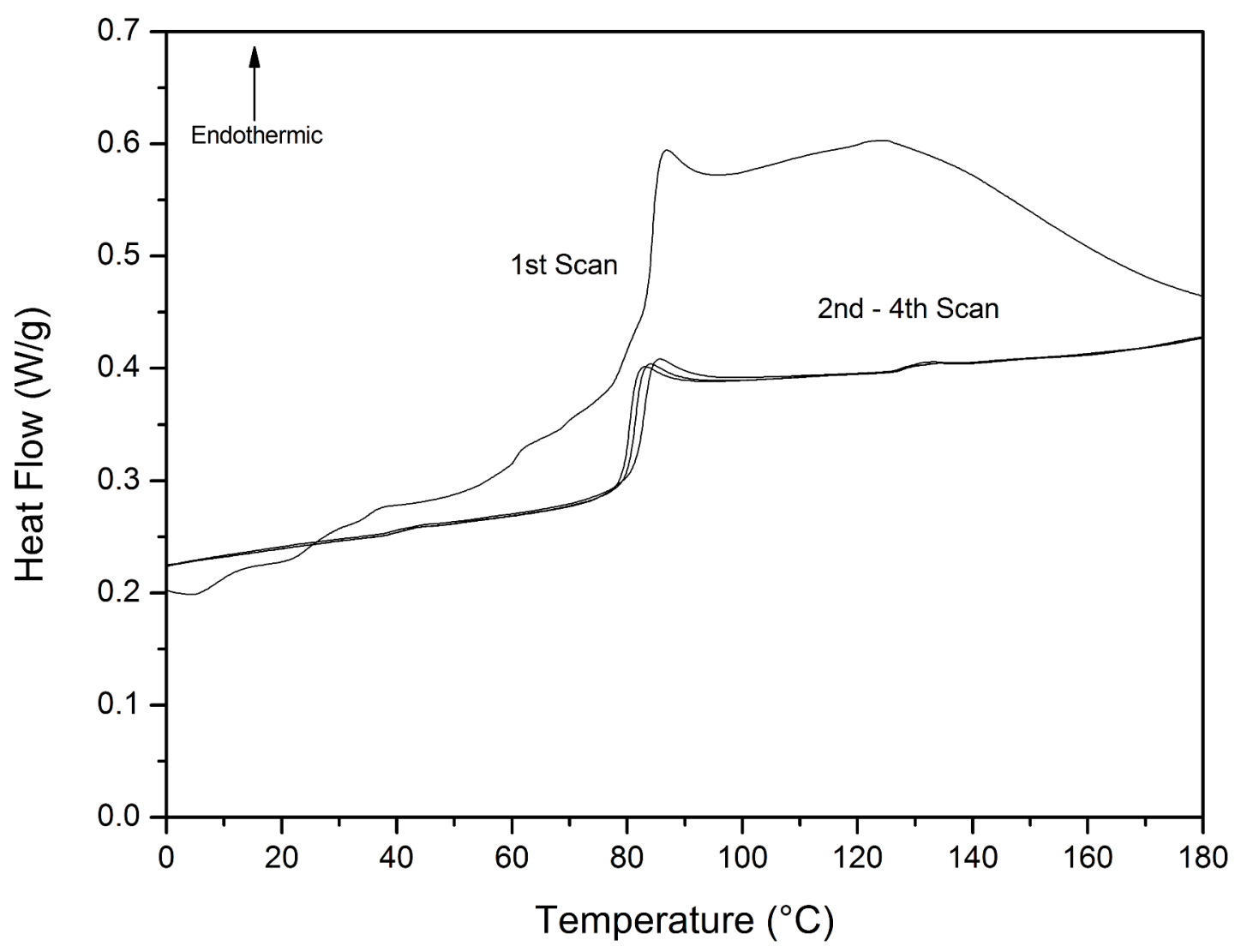

Figure 3 (Figure3.tif) 


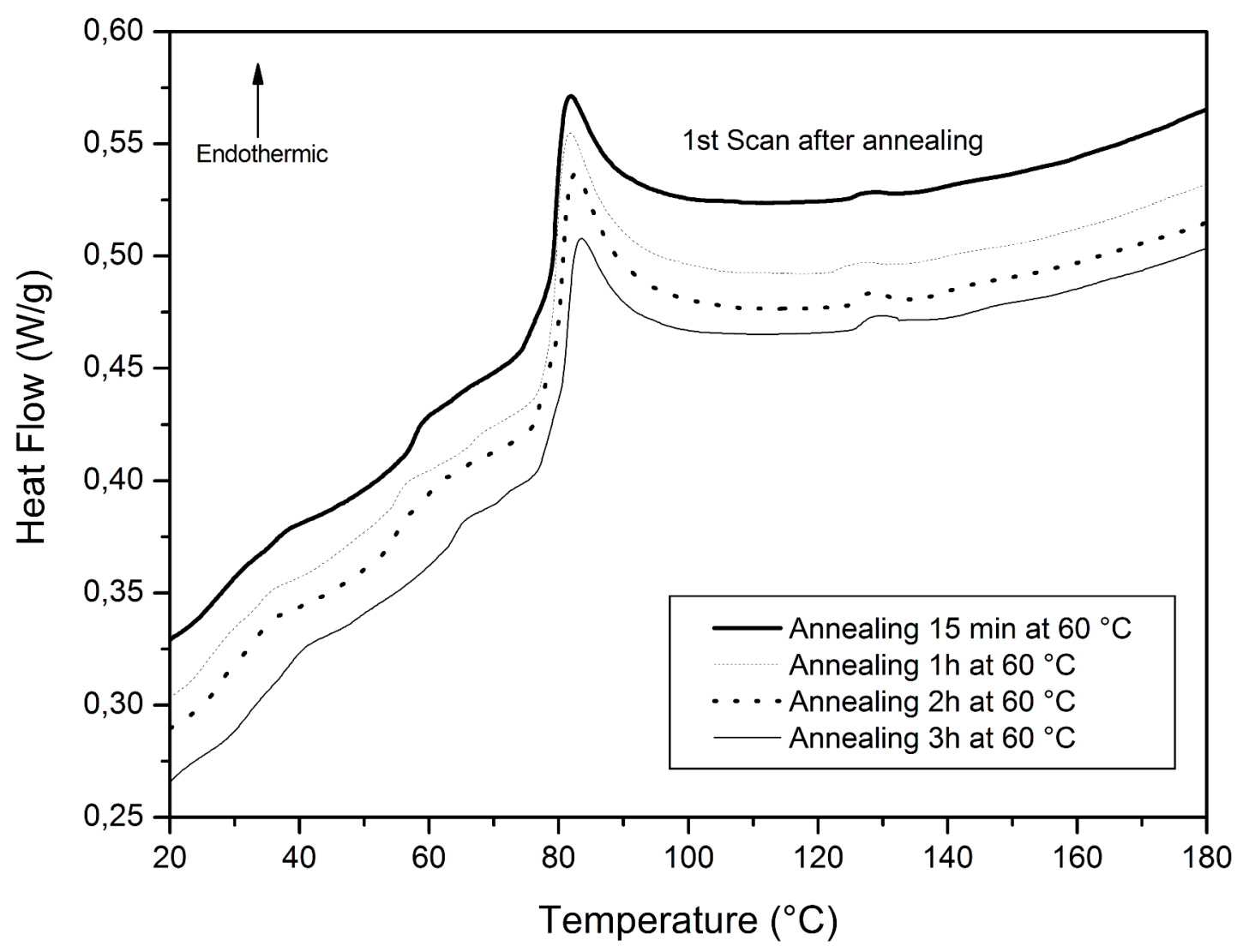

Figure 4 (Figure4.tif) 


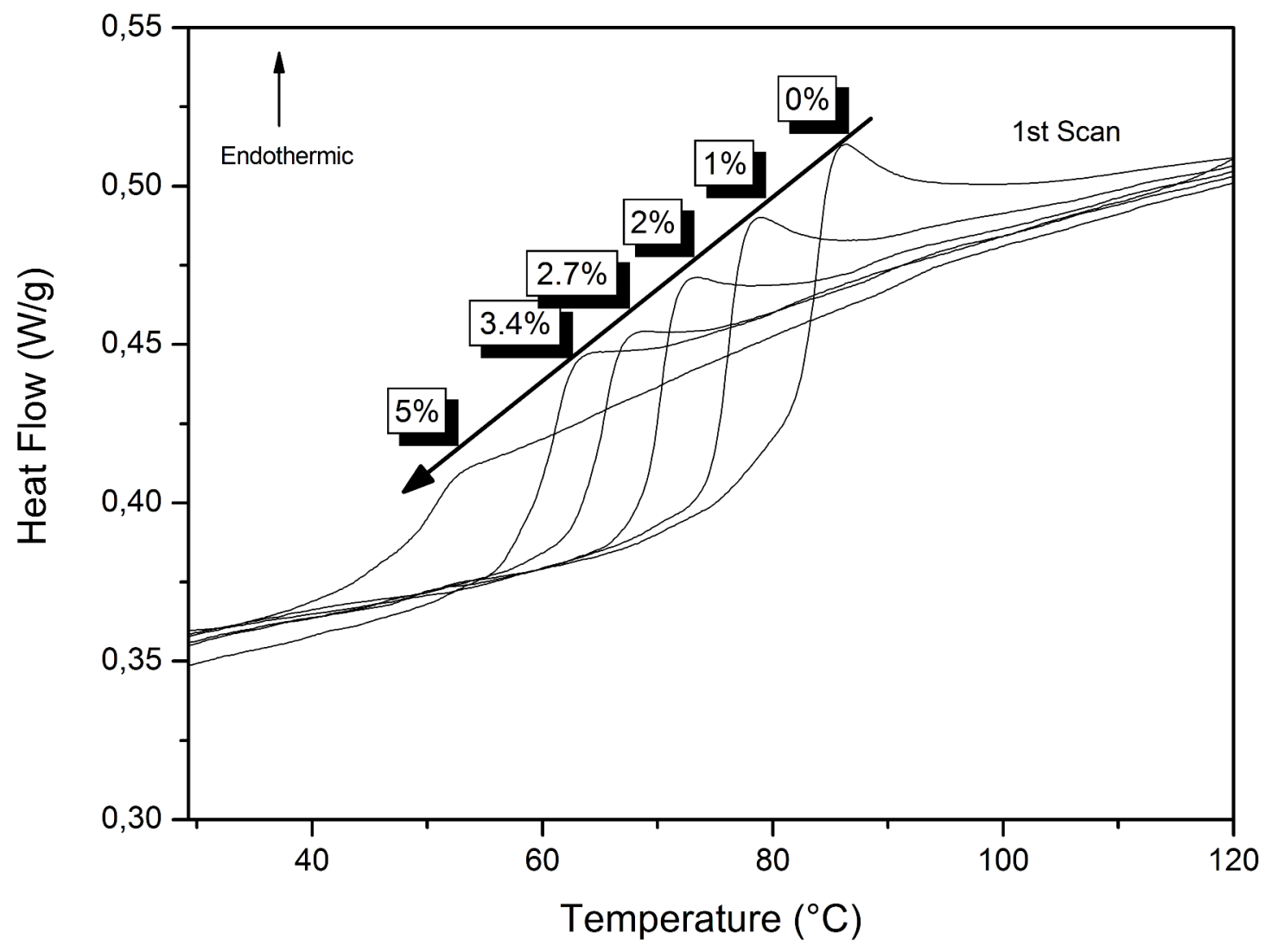

Figure 5 (Figure5.tif) 


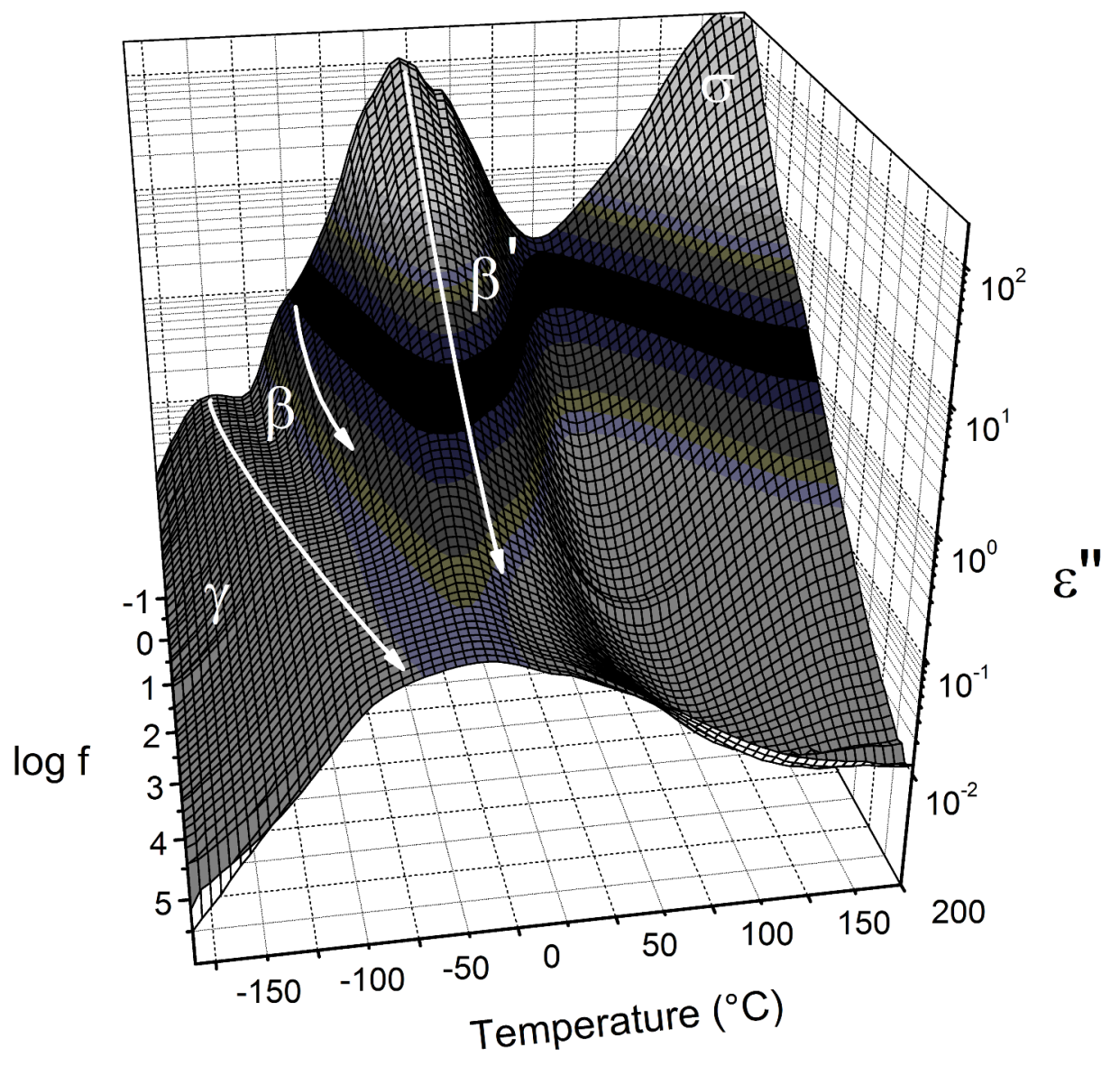

Figure 6 (Figure6.tif) 


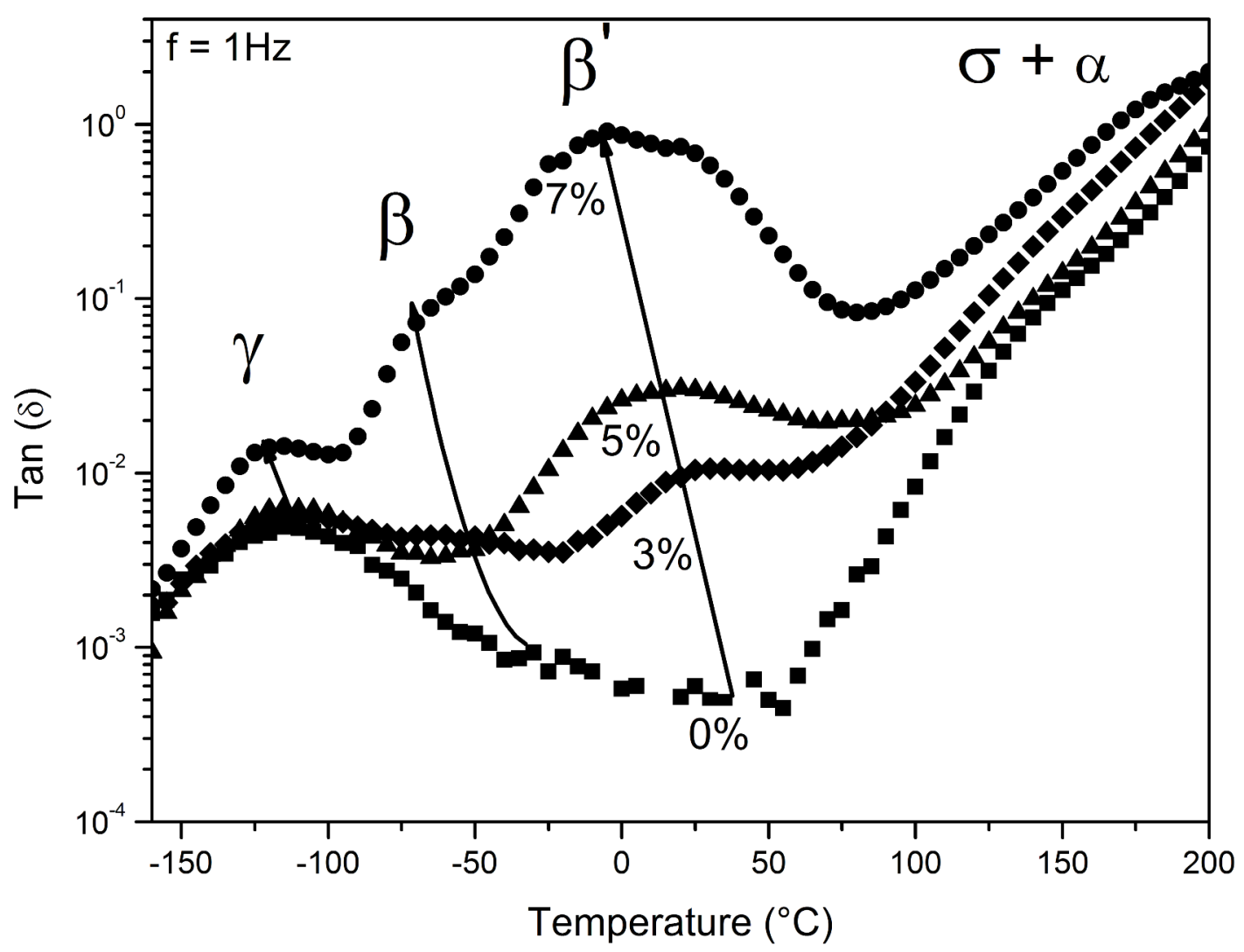

Figure 7 (Figure7.tif) 
Temperature $\left({ }^{\circ} \mathrm{C}\right)$

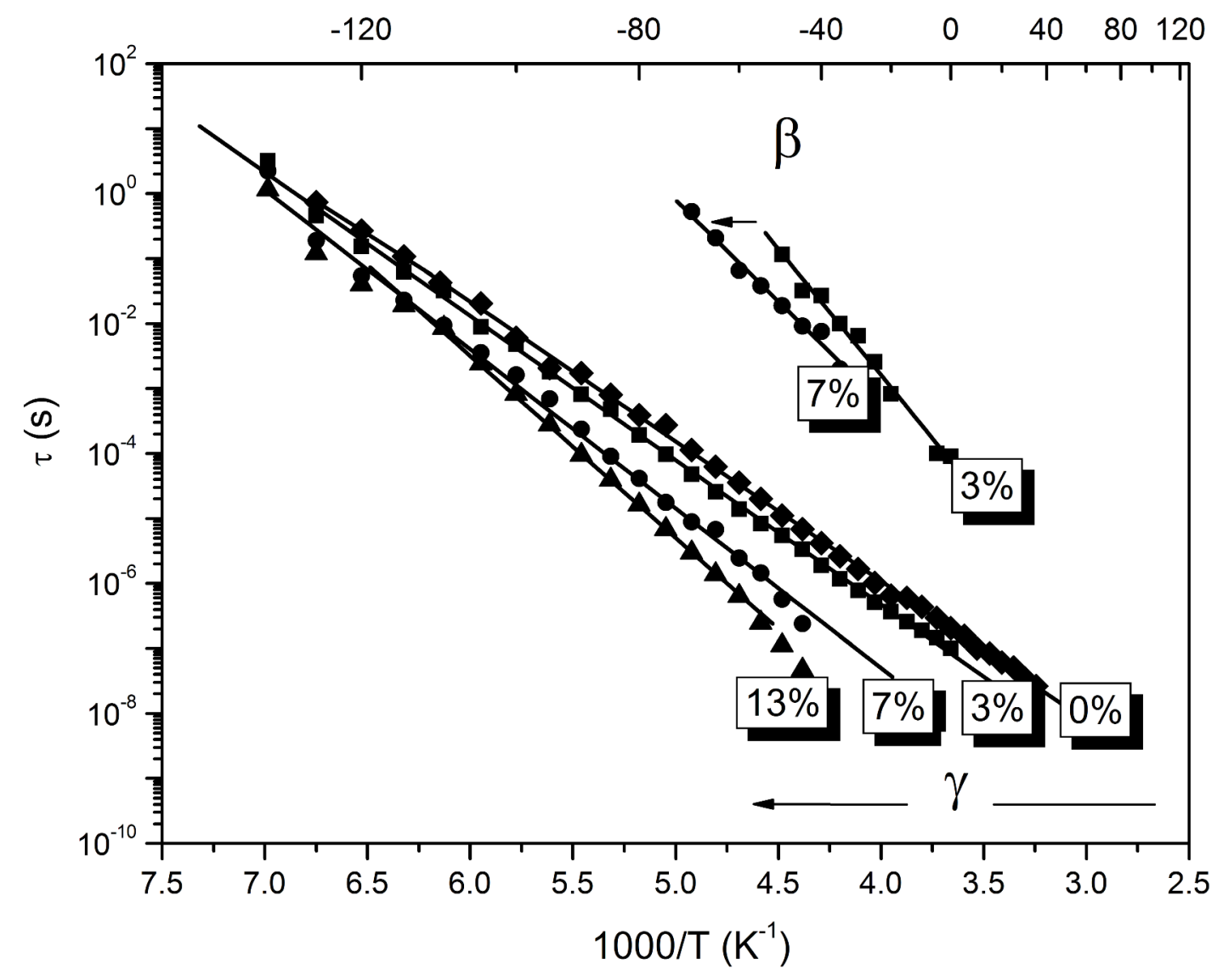

Figure 8 (Figure8.tif) 


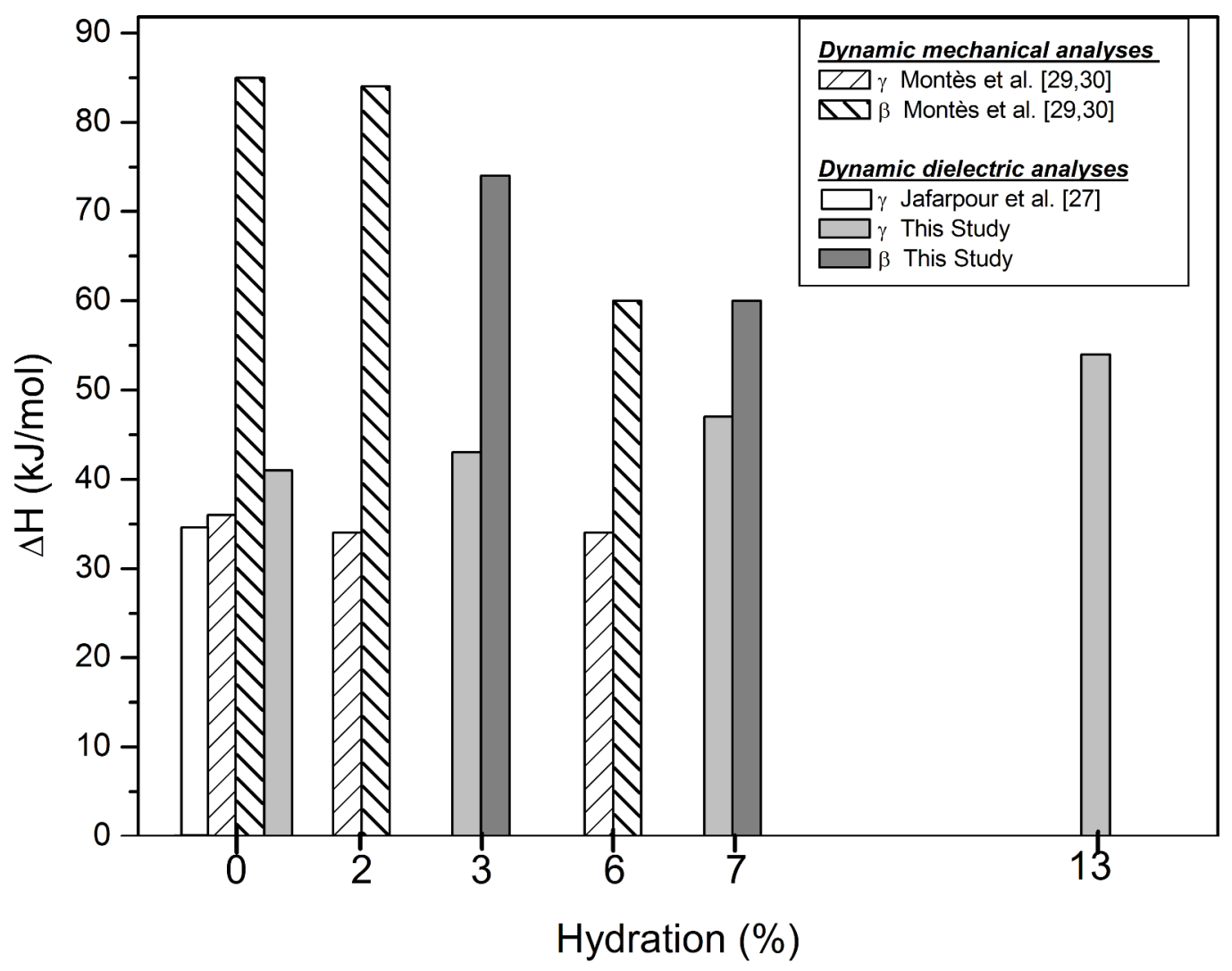

Figure 9 (Figure9.tif) 


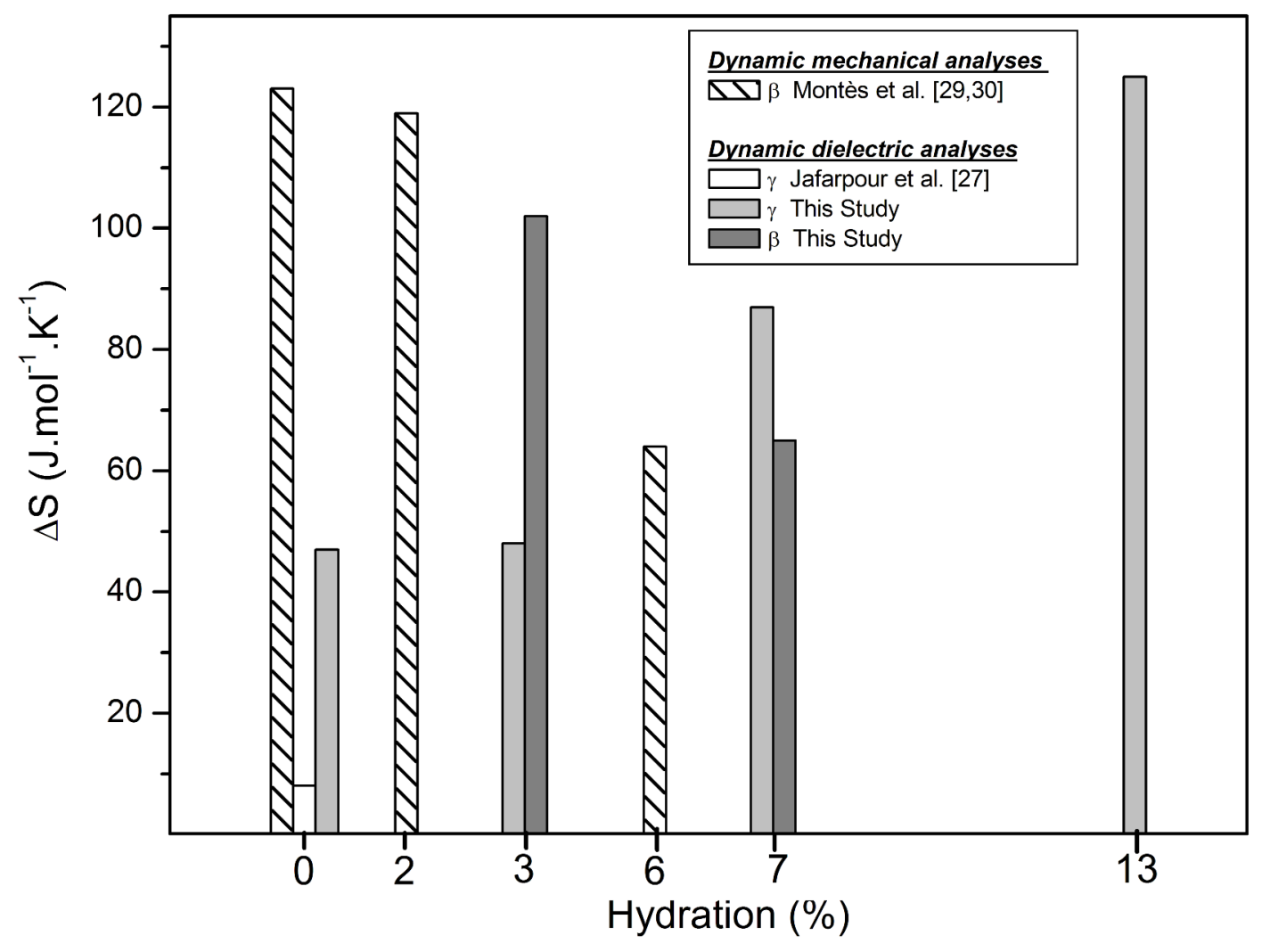

Figure 10 (Figure10.tif) 


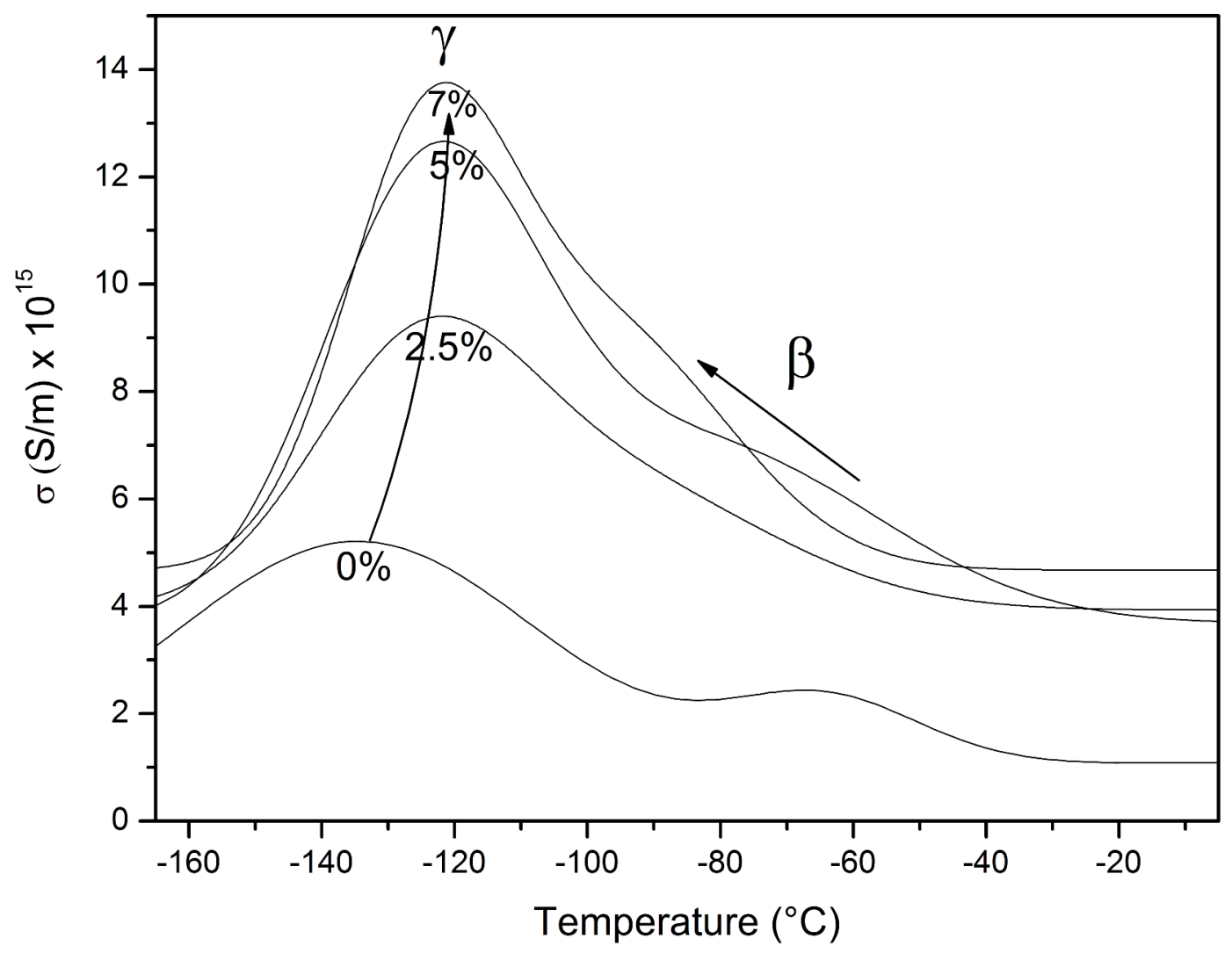

Figure 11 (Figure11.tif) 


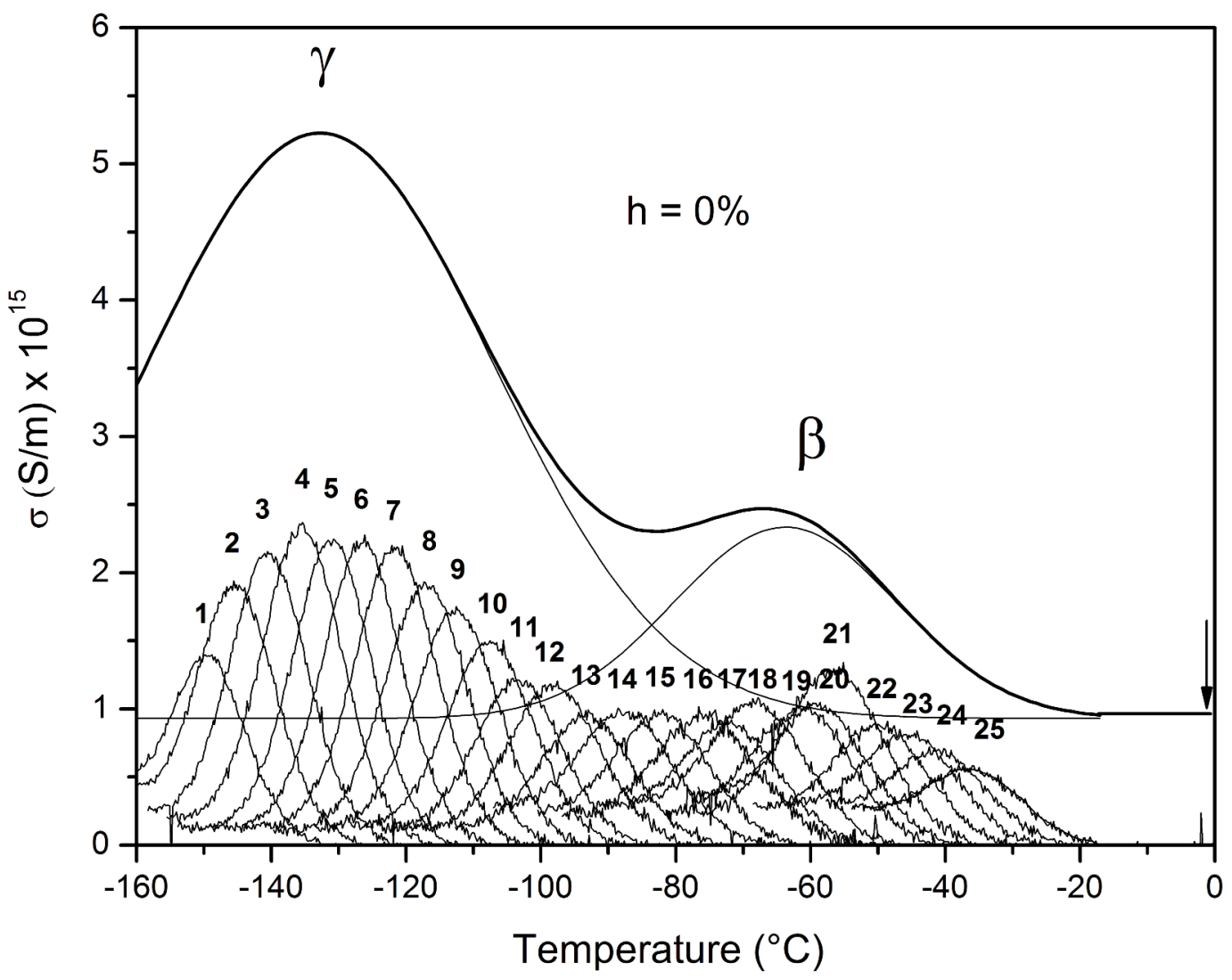

Figure 12 (Figure12.tif) 


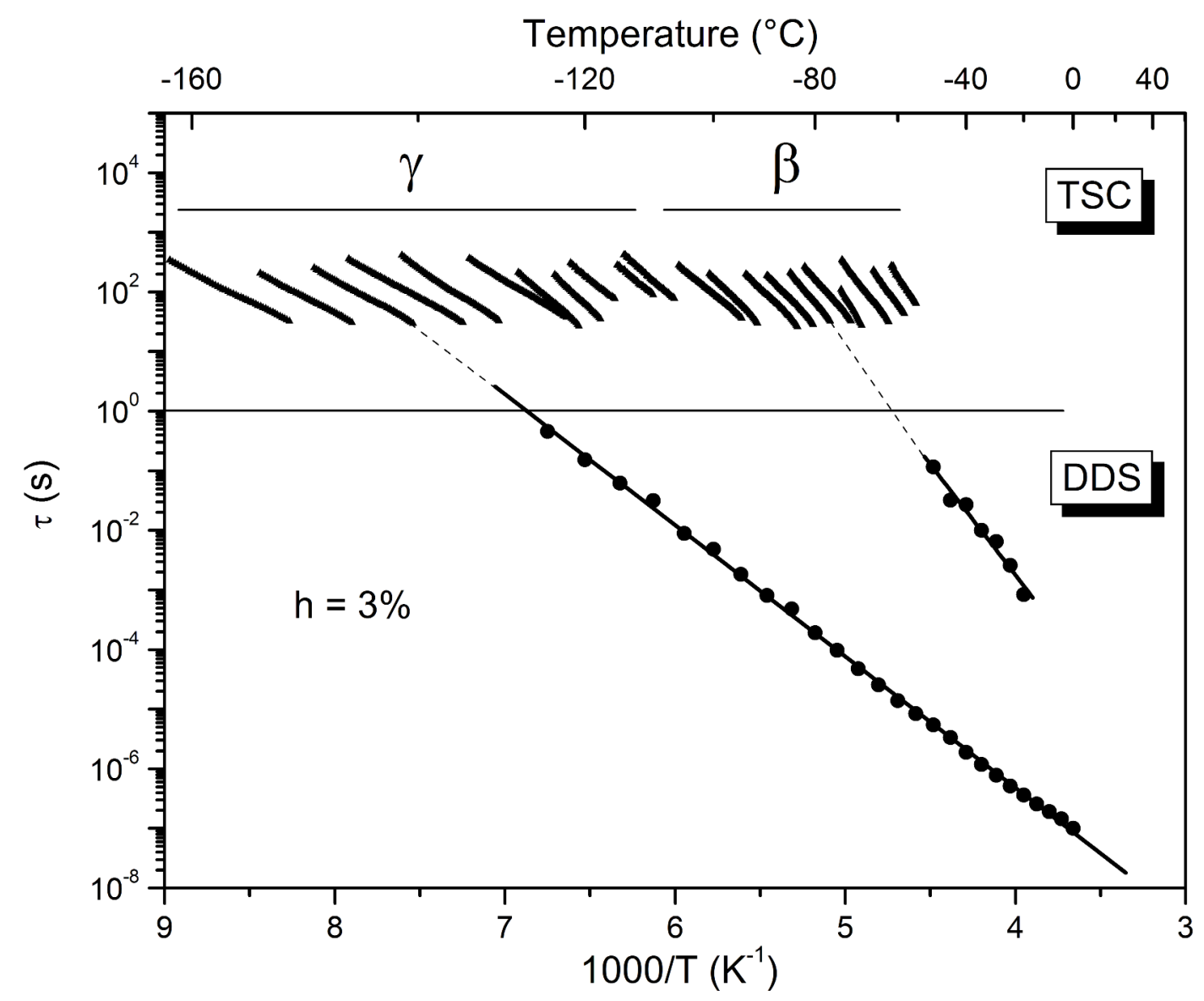

Figure 13 (Figure13.tif) 


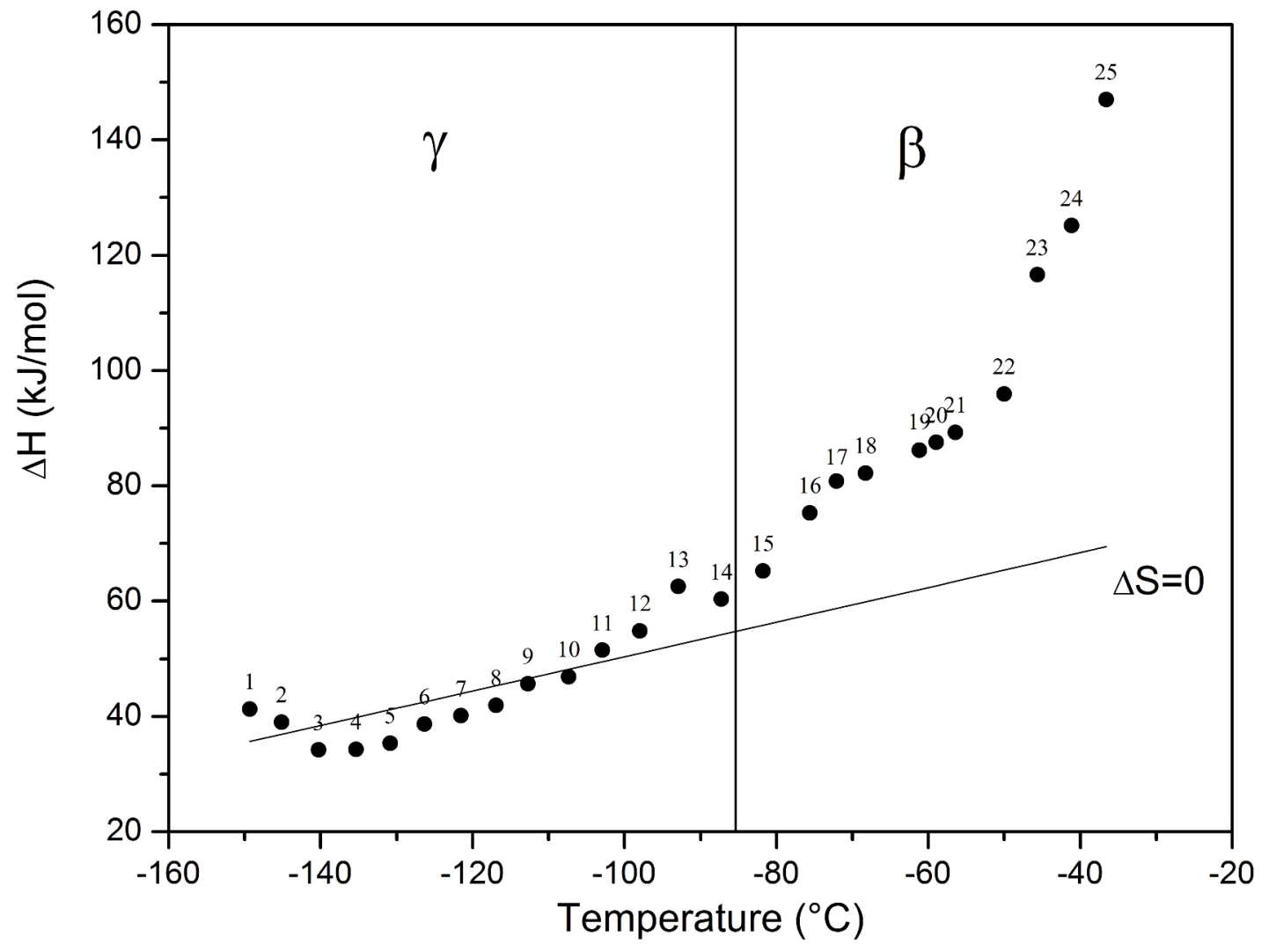

Figure 14 (Figure14.tif) 


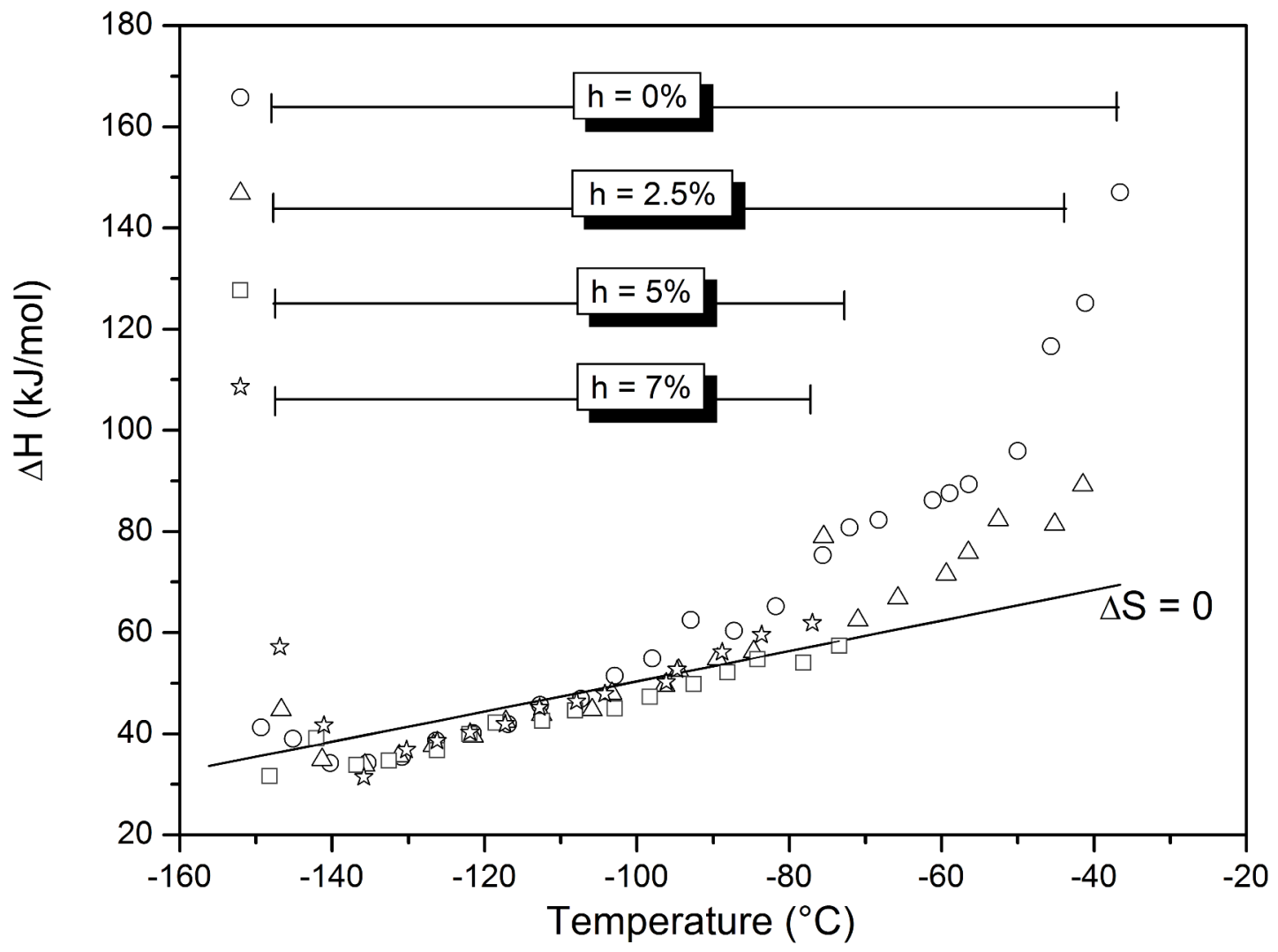

Figure 15 (Figure15.tif) 


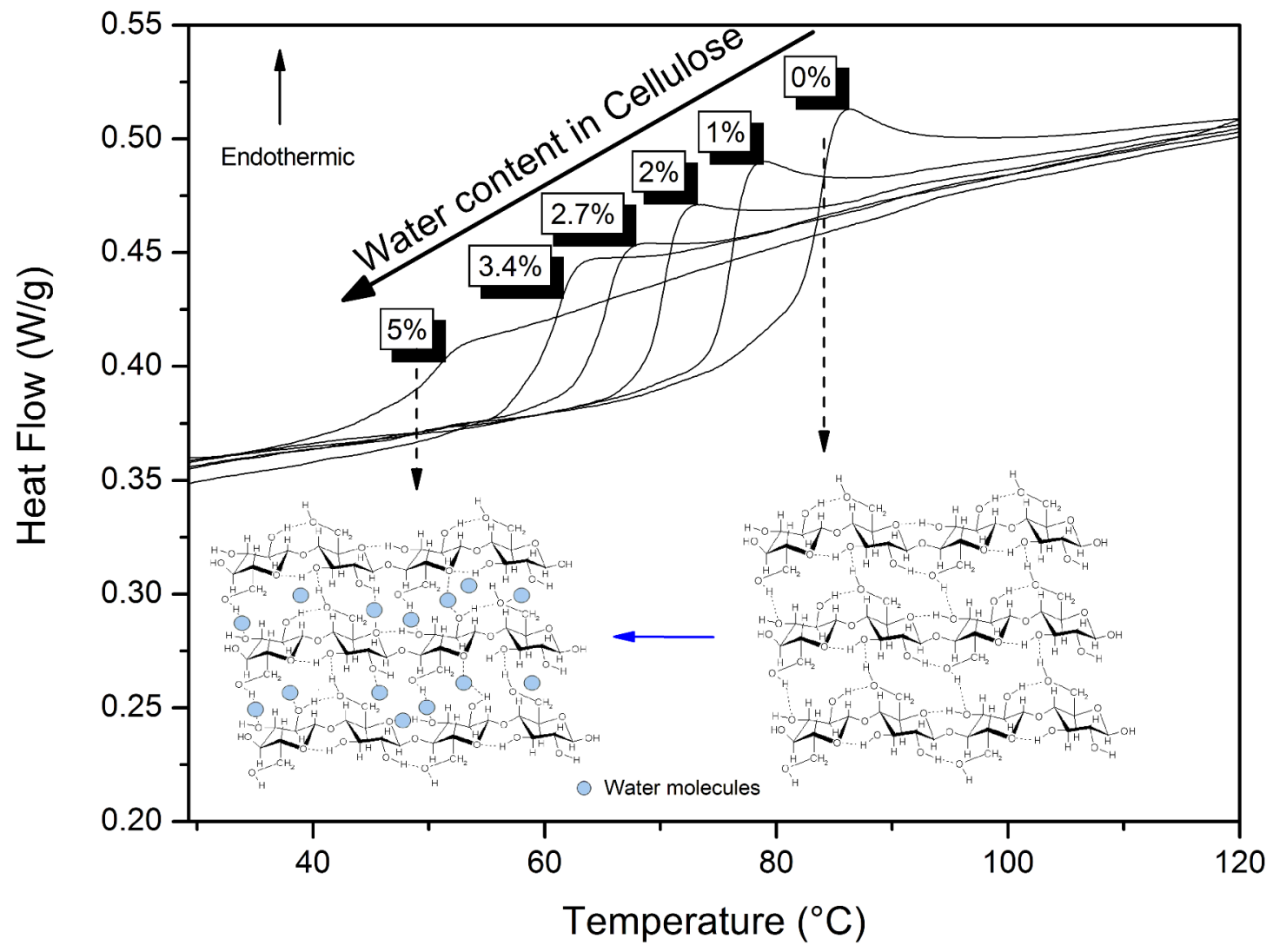

Figure 16 (Graphical Abstract.tif) 